\title{
Contribuição da inspeção visual com ácido acético e da captura híbrida II como métodos adjuntos à colpocitologia oncologica na detecção das lesões precursoras e/ ou do câncer cervical
}

\section{Contribution of visual inspection with acetic acid and hibryd capture II as adjunct methods to Pap smear in the detection of precursor lesion and/or cervical cancer}

\author{
Autora: Joana Fróes Bragança \\ Orientadora: Prof. ${ }^{a}$ Dr. ${ }^{a}$ Sophie Françoise M. Derchain \\ Co-Orientador: Prof. Dr. Luiz Carlos Zeferino
}

Dissertação de Mestrado apresentada à Pós-Graduação da Faculdade de Ciências Médicas da Universidade Estadual de Campinas para obtenção do Título de Mestre em Tocoginecologia, área de Tocoginecologia, em 6 de julho de 2004.

Objetivo: avaliar a contribuição da inspeção visual com ácido acético e da captura híbrida II como métodos adjuntos à colpocitologia oncológica na detecção das lesões precursoras ou câncer cervical. Sujeitos e Métodos: realizou-se um estudo descritivo de corte transversal e posteriormente validação de teste diagnóstico. Foram incluídas 809 mulheres atendidas no Centro de Atenção Integral à Saúde da Mulher (CAISM) da Universidade Estadual de Campinas que responderam a um questionário pré-estruturado e foram submetidas a exame ginecológico com coleta de material para colpocitologia oncológica $(\mathrm{CO})$, para detecção de papilomavírus humano de alto risco oncogênico por captura híbrida II $(\mathrm{CH}$ II); realizada inspeção visual, com aplicação de ácido acético a 5\% (IVA) e colposcopia com biópsia dirigida das áreas anormais. Para avaliar a associação entre cada exame e a colposcopia foi calculada a razão de prevalência com intervalo de confiança a $95 \%$ e para o desempenho dos exames de rastreamento foram calculadas a sensibilidade e a especificidade, VPP e VPN. Resultados: das 809 mulheres avaliadas, 12\% apresentavam anormalidades à inspeção visual com ácido acético, 19\% tinham captura híbrida II positiva, 7\% apresentaram alterações na colpocitologia oncológica e 39
$(4,8 \%)$ apresentaram biópsia com lesões associadas ao HPV e, destas, 12 com lesões de alto grau. A IVA apresentou sensibilidade maior que $70 \%$ e especificidade de $91 \%$, tendo o melhor desempenho como método isolado para a detecção de NIC 1 ou mais. A sensibilidade da $\mathrm{CH}$ II foi maior para a detecção de neoplasia intra-epitelial 2 ou mais. A especificidade da $\mathrm{CO}$ foi superior à dos outros dois métodos, embora sua sensibilidade tenha sido significativamente inferior. A sensibilidade da associação dos três métodos para o diagnóstico de NIC 1 ou mais foi significativamente melhor do que a da $\mathrm{CO}$ isoladamente ou associada à IVA. Já para a detecção de lesões de alto grau, a associação da $\mathrm{CH}$ II à $\mathrm{CO}$ foi o método que apresentou melhor sensibilidade sem perda na especificidade. Conclusão: a inspeção visual com ácido acético contribuiu significativamente para a detecção de doença histológica, embora a associação da colpocitologia oncológica e captura híbrida tenha sido o melhor método para detecção de lesões de alto grau.

PALAVRAS-CHAVE: Colo do útero: lesões préneoplásicas; Câncer: rastreamento; Colo uterino: câncer; Colposcopia; Captura híbrida II; Inspeção visual com ácido acético

\section{Dopplerfluxometria do ducto venoso entre a $10^{\mathrm{a}}$ e $14^{\mathrm{a}}$ semanas de gestação: elaboração da curva de normalidade}

\section{Ductus venosus Doppler flow measurements at 10-14 weeks of gestation: reference values}

Aluno: Luciano da Silva Teixeira

Orientador: Prof. Dr. Mario Jorge Barreto Viegas Castro

Dissertação apresentada ao Curso de Pós-graduação do Departamento de Ginecologia e Obstetrícia da Faculdade de Medicina da Universidade Federal de Minas Gerais, para obtenção do título de Mestre, em 18 de junho de 2004.

Objetivos: avaliar o fluxo sangüineo no ducto venoso durante as diferentes fases do ciclo cardíaco em gestações entre a $10^{\mathrm{a}}$ e a $14^{\mathrm{a}}$ semanas, a fim de estabelecer faixas de referência dos seguintes velocidades e indices: 1 - Pico de velocidade da sístole ventricular - onda
S; 2 - Pico de velocidade na diástole ventricular - onda D; 3 - Pico de velocidade na contração atrial - onda A; 4 - Média das velocidades máximas durante o ciclo cardíaco - Tmax.; 5 - Índice de pulsatilidade para veias IPV; 6 - Índice de pico de velocidades para veias - IPVV. 
Material e Métodos: trata-se de um estudo transversal e retrospectivo no qual foram incluídos 843 fetos provenientes da clinica Gennus de Belo Horizonte, com idade gestacional entre 10 e 14 semanas confirmada através do comprimento cabeça-nádegas $(\mathrm{CCN})$ entre 38-84 mm. Foram incluídos recém-nascidos a termo, vivos, fenotipicamentes normais. A localização dopplerfluxométrica do ducto venoso foi feita através de corte longitudinal, para-sagital direito no nível do tronco, onde observa-se a sua união à veia cava inferior através de seu padrão característico de alta velocidade de fluxo, fato que levou à sua representação com expressiva intensidade de cor. A janela do Doppler pulsátil foi colocada na porção média do ducto, entre o ducto proximal (seio umbilical) e a porção distal (união do ducto venoso e veia cava inferior). Curvas de referência foram construídas para todos os parâmetros estudados. Resultados: a velocidade do fluxo sangüíneo no ducto venoso aumentou na sístole ventricular (onda S), na diastole ventricular (onda D), na contração atrial (onda
A) e na Tmax, com o avançar da idade gestacional. Em relação ao comportamento do IPVV e do IPV, não se observou alteração com o evoluir da gestação, tendo o IPV mostrado uma tendência (sem significância estatística) a aumento gradual até o CCN de $63 \mathrm{~mm}$ (12 semanas e seis dias), quando ocorreu queda progressiva. Conclusão: $O$ estudo da velocidade do fluxo sangüineo no ducto venoso demostrou aumento progressivo nas diferentes fases da onda, secundário a alterações hemodinâmicas, tanto na pré-carga como na pós-carga, entre a $10^{\mathrm{a}}$ e a $14^{\mathrm{a}}$ semanas de gestação. Em relação ao estudo dos índices estudados, o IPV apresentou tendência a aumento gradual até o CCN de $63 \mathrm{~mm}$, quando ocorreu queda progressiva. O IPVV não apresentou correlação com o aumento do CCN entre 10 e 14 semanas de gestação.

PALAVRAS-CHAVE: Ducto venoso; Gravidez normal; Dopplervelocimetria

Resumos de Tese

\section{Efeito imuno-histoquimico, molecular e morfológico das isoflavonas no útero de ratas}

\section{The imunohistochemistry molecular and morphological effectcs of isoflavones on the rat uterus}

Autora: Rejane Mosquette

Orientadores: Prof.Dr. Manuel de Jesus Simões

Prof.Dr. José Maria Soares Junior

Tese apresentada à Universidade Federal de São Paulo - Escola Paulista de Medicina, para obtenção do título de Mestre, em 24 de novembro de 2004

Objetivos: avaliar os efeitos das isoflavonas no útero de ratas castradas, comparando-os aos dos estrogênios por técnicas histológicas, morfológicas, imunohistoquímicas e de biologia molecular. Métodos: ratas adultas após 28 dias de castração foram divididas ao acaso em sete grupos iguais: Gp animais que receberam propilenoglicol; G10, G50, G100, G300 e G600 animais que receberam respectivamente $10,50,100,300$ e $600 \mathrm{mg} / \mathrm{kg}$ de extrato de soja $^{1}$ enriquecido com isoflavonas e GE animais tratados com estrogênios conjugados eqüinos $(200 \mathrm{mg} / \mathrm{kg})$. Todos os animais receberam por 21 dias consecutivos por gavagem os produtos, sendo sacrificados sob anestesia ao final. Fragmentos dos úteros foram mergulhados em formol a $10 \%$ para estudo histológico e imuno-histoquimico (fator de crescimento vascular endotelial - VEGF, e de proliferação nuclear - PCNA). Outros foram rapidamente mergulhados em nitrogênio líquido para extração do RNA e avaliação do gene do VEGF pela técnica da transcriptase reversa (RT-PCR). Resultados: notamos que doses de estrato de soja igual ou superior a 300 $\mathrm{mg} / \mathrm{kg}$ estimulam a espessura do endométrio $(\mathrm{Gp}=$ $12,7 \pm 0,3 \mathrm{~mm}$; G300 = 75,7 $\pm 1,2 \mathrm{~mm}$ ). Os mesmos dados foram observados em relação a imuno-histoquimica para o PCNA (número de mitoses em 1000 células Epitélio luminal Gp $=4,2 \pm 2,8 ; \mathrm{G} 300=74,9 \pm 13,7$; epitélio glandular $\mathrm{Gp}=7,1 \pm 6,6 ; \mathrm{G} 300=95,7 \pm 4,9$; lâmina própria $\mathrm{Gp}=0,2 \pm 0,3 ; \mathrm{G} 300=20,4 \pm 1,8$ ) e para o VEGF (intensa positividade). No entanto para o RTPCR do VEGF doses iguais ou superiores a $50 \mathrm{mg} / \mathrm{kg}$ já mostraram a presença de nítidas bandas indicando ação trófica das isoflavonas. Os estrogênios apresentaram efeitos tróficos em todos os parâmetros estudados. Conclusões: as isoflavonas apresentam ação trófica sobre o útero de ratas castradas dependendo da dose administrada.

PALAVRAS-CHAVE: Isoflavonas; Endométrio; VEGF; Ciclo celular

\footnotetext{
${ }^{1}$ Extrato de soja cedido pela SP Farma, contendo 425,5 $\mathrm{mg}$ de isoflavonas por grama de extrato.
} 